\title{
Investigation into Cryogenic Tank Insulation Systems for the Mars Surface Environment
}

\author{
Wesley L. Johnson ${ }^{1}$, Daniel M. Hauser ${ }^{2}$, and David W. Plachta ${ }^{3}$ \\ NASA Glenn Research Center, Cleveland, $\mathrm{OH}, 44135$ \\ Steven G. Sutherlin ${ }^{4}$, Juan G. Valenzuela ${ }^{5}$, James W. Smith ${ }^{6}$, and Jonathan R. Stephens ${ }^{7}$ \\ NASA Marshall Space Flight Center, Huntsville, AL, 35812 \\ and \\ Brian F. Banker ${ }^{8}$ and Pooja S. Desai ${ }^{9}$ \\ NASA Johnson Space Center, Houston, TX, 77058
}

In order to use oxygen that is produced on the surface of Mars from In-Situ production processes in a chemical propulsion system, the oxygen must first be converted from vapor phase to liquid phase and then stored within the propellant tanks of the propulsions system. The oxygen must then be stored in the liquid phase for several years between when the liquefaction operations are initiated and when the ascent stage lifts off the Martian surface. Since the Space Exploration Initiative, NASA has been investing small sums of money into soft vacuum systems for Mars Applications. ${ }^{1}$ A study was done into these various insulation systems for soft vacuum insulation, to determine what types of systems might be best to further pursue. Five different architectures or cycles were considered: Aerogel based multilayer Insulation (MLAI), Space Evacuated Mars Vacuum Jacket (SEMOV) (also known as lightweight vacuum jacket), Load Responsive-Multilayer Insulation, Spray on Foam with multilayer insulation, and MLAI in SEMOV. Models of each architecture were developed to give insight into the performance and losses of each of the options. The results were then compared across six categories: Insulation System Mass, Active System Power (both input and heat rejection), Insulation System Cost, Manufacturability, Reliability, and Operational Flexibility. The result was that a trade between reliability and mass was clearly identified. Systems with high mass, also had high perceived reliability; whereas, systems with lower mass and power had a much lower perceived reliability. In the end, the numerical trades of these systems showed nominally identical rankings. As a result it is recommended that NASA focus its Martian insulation development activities on demonstrating and improving the reliability of the lightweight identified systems.

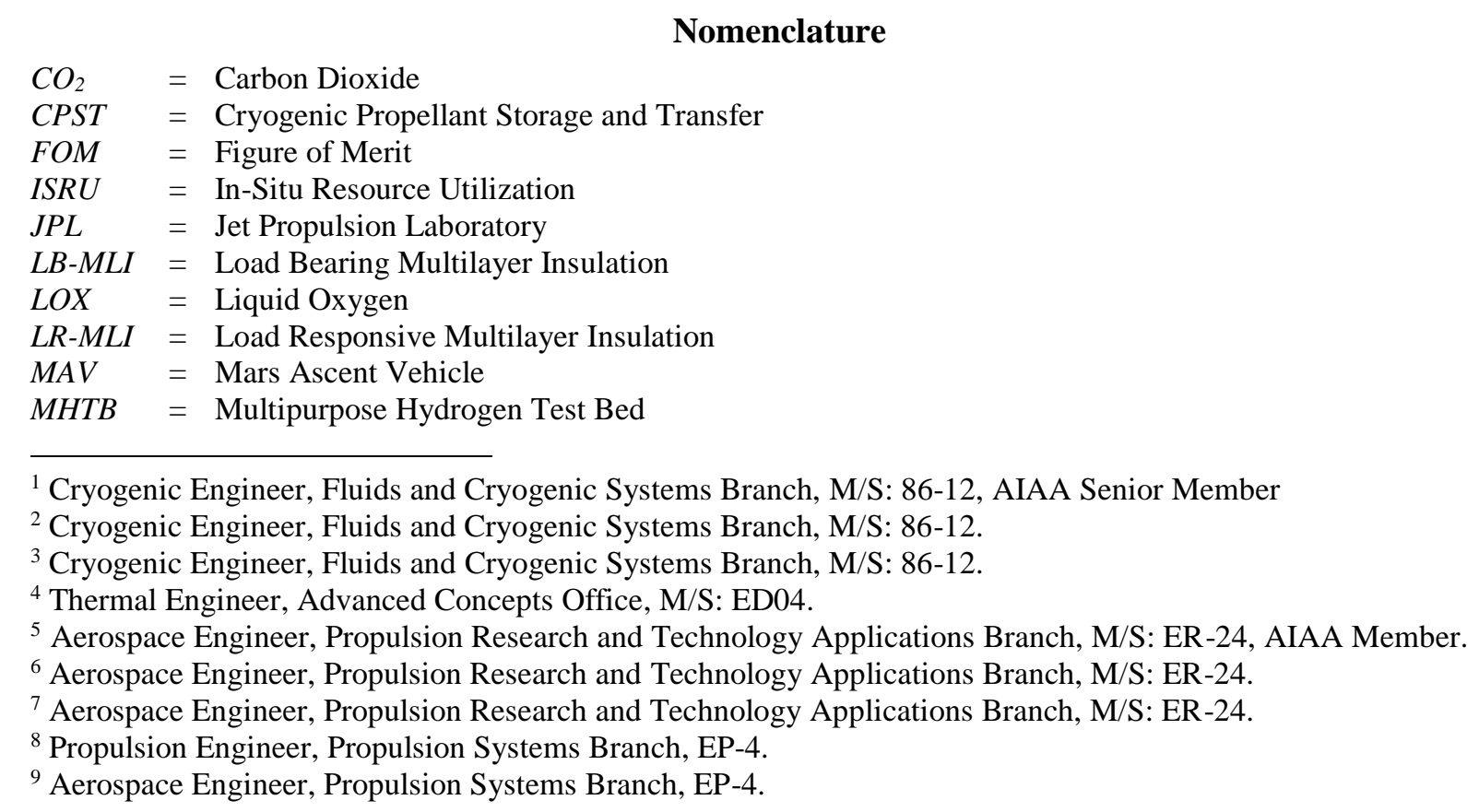




$\begin{array}{ll}\text { MLAI } & =\text { Mulilayer Aerogel Insulation } \\ M L I & =\text { Multilayer Insulation } \\ \text { SBIR } & =\text { Small Business Innovative Research } \\ \text { SEMOV } & =\text { Space Evacuated Mars Outer Vessel } \\ \text { SOFI } & =\text { Spray on Foam Insulation } \\ T R L & =\text { Technology Readiness Level } \\ V J & =\text { Vacuum Jacket } \\ W B T & =\text { Warm Boundary Temperature }\end{array}$

\section{Introduction}

I AUNCHING significant mass to Mars requires the launch of even more mass from the surface of Earth. LArchitectural studies show that placing a $\mathrm{kg}$ of mass on Mars requires between 7 and $11 \mathrm{~kg}$ launched from earth. Returning said kg from Mars to Earth requires a similar mass ratio on the surface of Mars. ${ }^{2}$ A quick calculation shows that returning mass from the surface of Mars is an extremely expensive proposition. Every effort must be made to reduce the mass needed. Based on the traditional rocket equation, the lowest mass fraction of propellant capable of returning large masses is nearly $75 \%$. For an oxygen/methane based propulsion system over $75 \%$ of that propellant mass is liquid oxygen. Thus by producing oxygen on the surface, the mass of the return vehicle required to be delivered to the surface is reduced by more $55 \%$. Additional production of the methane as well can reduce the mass by up to the full propellant mass or $75 \%$. However, this does require extra hardware to produce the propellant. The benefits of ISRU is shown graphically in Figure 1.

Over the last twenty plus years (since the Space Exploration Initiative), NASA has been developing technology to allow for the mass production and storage of propellants on the surface of both Mars and the Moon. Specifically, insulation systems have been investigated for a regime known as "soft vacuum". Soft vacuum is the regime between 0.1 and 10 Torr where gas conduction is the dominant mode of heat transfer within the insulation system, but it is just on the cusp of continuum flow within that system.

Based on generic system performance parameters of the current state of the art (spray on foam insulation and

\section{Minimum Lander Size (mt)}

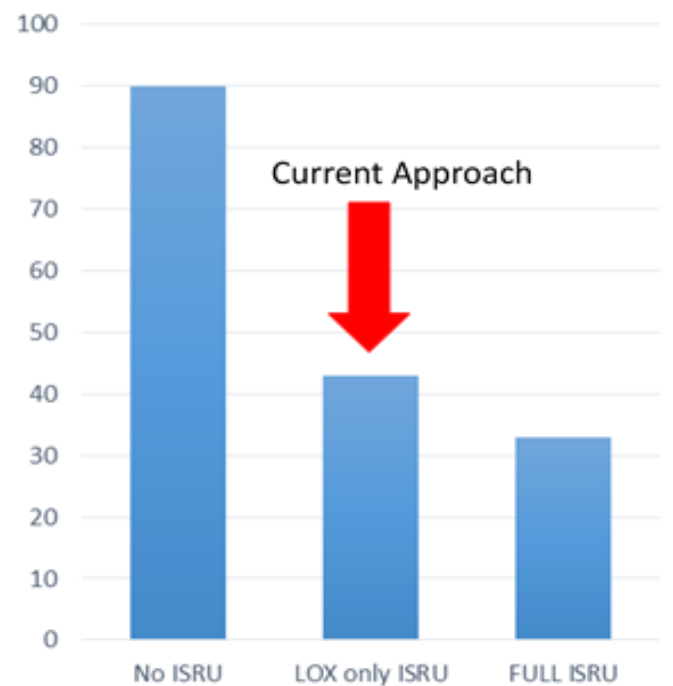

Figure 1: Relative Lander sizes using no ISRU, Liquid Oxygen (LOX) production only, and production of both Liquid Oxygen and Liquid Methane. $^{3}$ multilayer insulation), reference 4 showed the trade between mass and thermal performance for insulation systems applied to the Mars Ascent Vehicle. These trades started as the baseline material and were further refined during this activity.

The team used rough order magnitude sizing principles guided by the basic physical processes in addition to existing Mars ascent vehicle thermal models to determine the sizing (mass and power) of the insulation system and entire vehicle with the different options.

The details of the process described are summarized in the remainder of the report.

\section{Insulation Systems Options}

Six different insulation systems were analyzed for comparison: Aerogel based multilayer Insulation (MLAI), Space Evacuated Mars Outer Vessel (SEMOV), Load Responsive-Multilayer Insulation, Earth Atmosphere Vacuum Jacket, Spray on Foam with MLI, and MLAI in SEMOV. Of those six, the Earth Atmosphere Vacuum Jacket was thrown out prior to doing any of the trades due to excessive mass penalties occurred.

\section{A. Ground Rules and Assumptions}




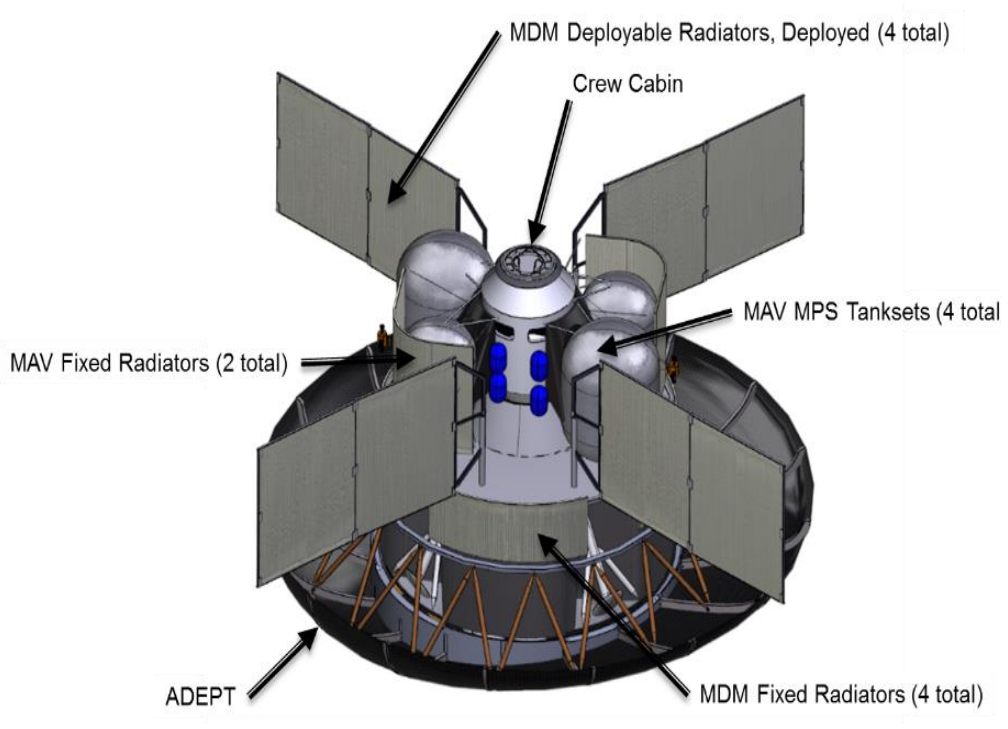

Figure 2: MAV Surface Configuration

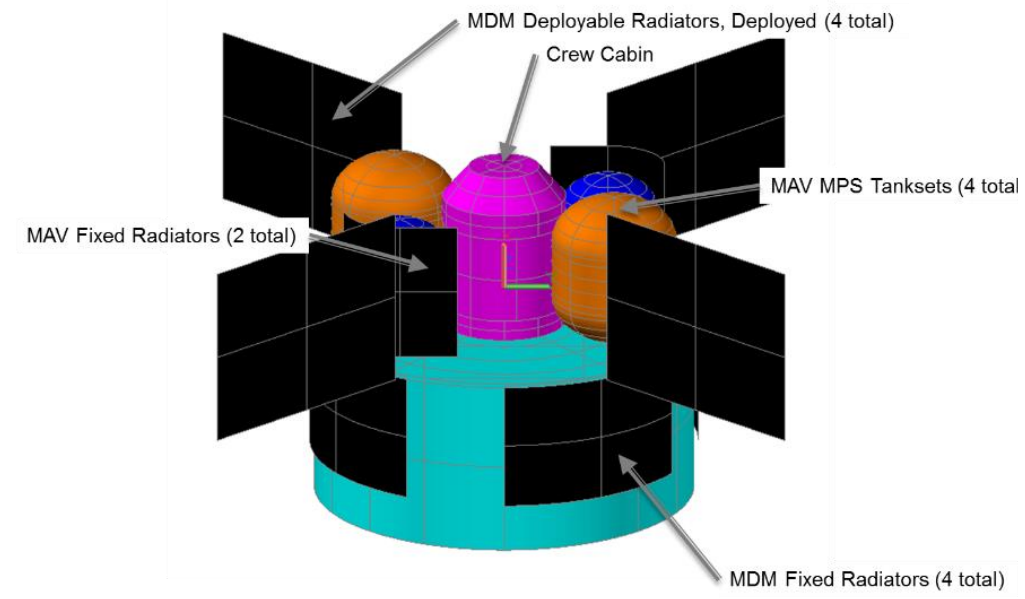

Figure 3: MAV Thermal Desktop Model for Surface Configuration
Several assumptions were used to set a level playing field across all insulation system options. These are not necessarily the final requirements, but represented the system as best as was known at the time of starting the analysis to get results that could be compared. The existing thermal desktop model of the MAV (see Figure 2 and Figure 3) was used to calculate the heat loads through the vehicle. The thermal conductivity or effective emissivity for each option was put into the model and used to calculate system heat loads. Heat load margins were $25 \%$ on the calculated values.

The basic environmental assumptions that went into the model are: Mars at perihelion, a landing site latitude of $24^{\circ} \mathrm{S}$, and a solar flux of 717 $\mathrm{W} / \mathrm{m}^{2}$. The Mars surface optical properties were an Albedo of 0.22 and an Emissivity of 0.97. The insulation outer layers in all cases were a $10 \mathrm{~mm}$ sheet of aluminized Teflon (absorptivity of 0.17 - adjusted for $10 \%$ dust coating based on discussions with JPL, and emissivity of 0.85). Properties were derived from various sources and put into the model to serve as the insulation system trades. No margin is shown in the numbers calculated in Table 1.

As the system is required to maintain zero-boil-off for long periods of time, the heat load through the insulation (and other factors) drive the lift required of the cryocooler system. The Mars architecture team baselined the development of a single cryocooler of approximately $150 \mathrm{~W}$ at $90 \mathrm{~K}$, using multiple cryocoolers where needed. ${ }^{3}$ Thus as the heat load of the tanks increased, cryocoolers were added and the number of cryocoolers is proportional to the heat load. This is reflected from both a mass and power perspective (the input power to the cryocoolers is directly proportional to the number of cryocoolers needed). Mass for cryocoolers needed for the liquefaction portion of the mission are not included in this count.

The mass of the power systems were not calculated with every option. While it would have been preferred to determine a total system mass, this was not feasible given the resources of the team. For this reason the team determined to track separate items for insulation mass and active power system mass/input power. Given the direct tie between active power system mass, input power, and insulation system heat load, this seemed to be the best grouping separate from insulation system mass.

\section{B. Spray on Foam Insulation (SOFI) and Multilayer Insulation (MLI)}

The original baseline insulation system for the lander was Spray on Foam Insulation with Multilayer Insulation on the outside of it (see Figure 4). This has been the baseline insulation system since the development of the MHTB test article in the mid-1990s. ${ }^{5}$ The main driving factor of the SOFI, was to keep the surface of it above $145 \mathrm{~K}$ to prevent solidification of carbon dioxide. This drove SOFI thickness to several inches and incurred a substantial amount of 
both mass and boil-off from the heat load through the system. The SOFI thickness required was 81 mm with an MLI thickness of 53 mm (60 layers).

\section{Multilayer Insulation}

Aerogel

Multilayer Aerogel Insulation (MLAI) was developed by Aspen Aerogels through multiple Small Business Innovative Research (SBIR) awards as a method of incorporating reflective shields into their low conductivity aerogel blankets. The most recent SBIR was a Phase II, where they developed a C40 spacer that can be used to replace MLI spacers at $2 \mathrm{~mm}$ thick. Figure 5 shows the cross section of an MLAI blanket on a MAV tank. Test results from the SBIR are shown in Figure 6 comparing the MLAI (A193) to SOFI, aerogel blankets with no reflectors, and traditional MLI blankets. The heat flux for four layers was $2.2 \mathrm{~W} / \mathrm{m}^{2}$. Additionally, the MLAI survived Vibration testing in both in-plane and normal according to the Cryogenic Propellant Storage and Transfer (CPST) project's random vibration environment profile. ${ }^{6}$ These results suggested that MLAI might be a good insulation system for the soft vacuum environment of Mars. A system was defined of $50 \mathrm{~mm}$ thick (40 layers) MLAI which had an areal density of $8.0 \mathrm{~kg} / \mathrm{m}^{2}$, an orbital heat flux (an assumed warm boundary temperature (WBT) of $250 \mathrm{~K}$ ) of 0.25 $\mathrm{W} / \mathrm{m}^{2}, 40 \mathrm{~W} / \mathrm{m}^{2}$ on the earth surface and $10 \mathrm{~W} / \mathrm{m}^{2}$ on the surface of Mars. This seemed to be a fair balance between mass and heat load on the system.

However, since then, testing of aerogels in $\mathrm{CO}_{2}$ environment has shown that there would be significant absorption of $\mathrm{CO}_{2}$ (see Figure 7), the sharp spikes in the data indicate in both carbon dioxide and argon where phase change starts to occur in the insulation. ${ }^{7}$

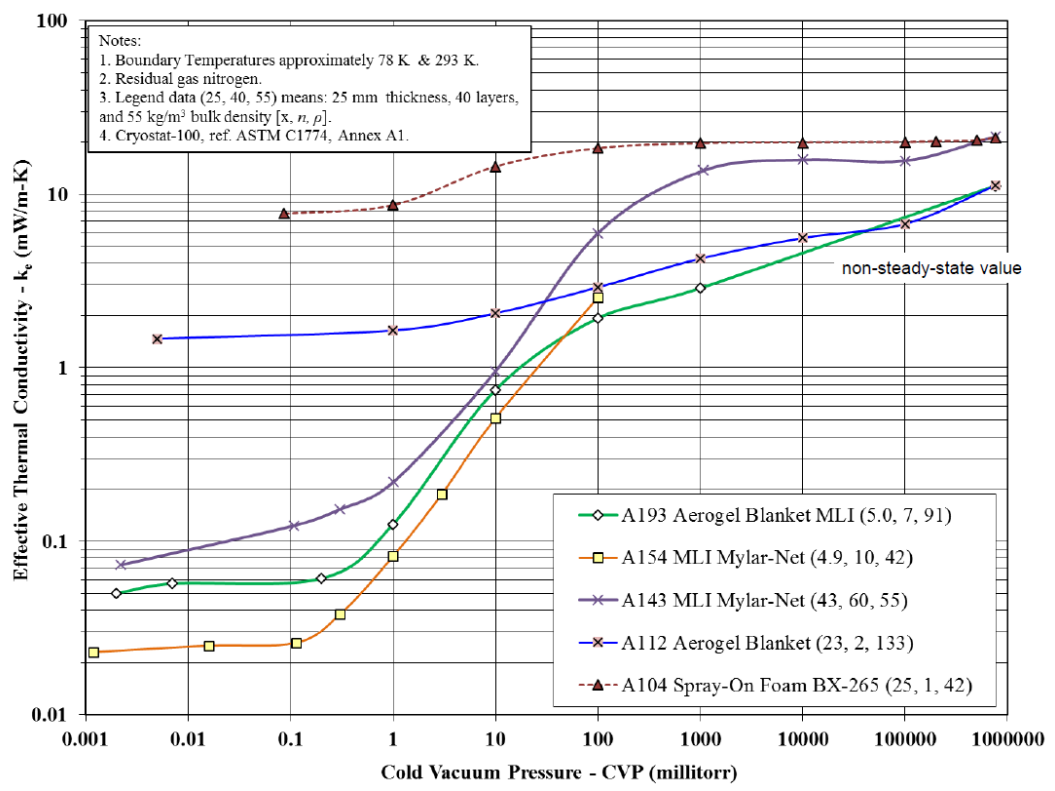

Figure 6: Thermal test results for MLAI (see A193). ${ }^{5}$ 


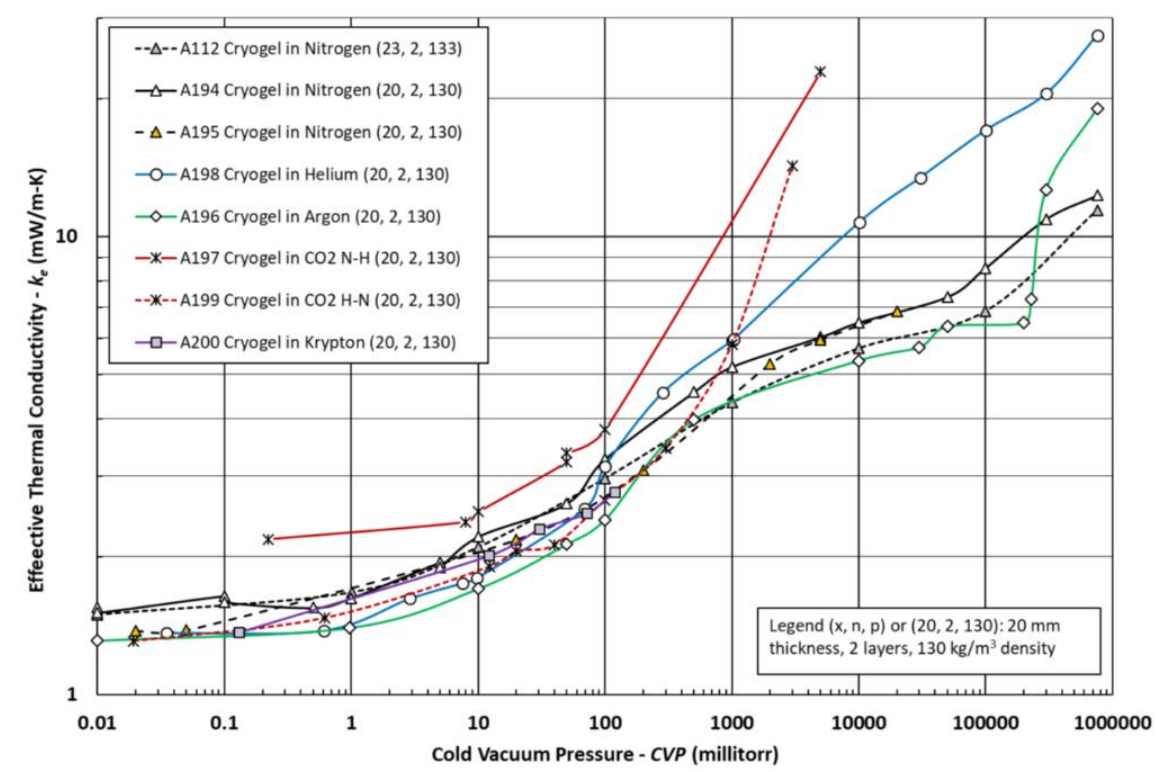

Figure 7: Effective thermal conductivity as a function of pressure of aerogel in multiple different background gasses. ${ }^{6}$

\section{Space Evacuated Mars Outer Vessel (SEMOV)}

The Space Evacuated Mars Outer Vessel (SEMOV) was first mentioned in concept by Plachta, Tucker, and Hoffman in $1993 .{ }^{8}$ An outer vessel (or vacuum jacket, $\mathrm{VJ}$ ) is designed to operate in the Mars atmosphere (see Figure 8). On the launch pad and in the Earth atmosphere, it is purged with a dry inert gas such as nitrogen. During launch and transit to Mars, it is evacuated to the deep space environment. Prior to descent to the Mars surface, the annulus is locked up and the vacuum is held for the duration of the mission. This allows the pressure boundary to be designed for $\sim 10$ torr and not 760 torr (Earth atmospheric pressure). It is shown in the trades as "Improved $2016 \mathrm{MLI} / \mathrm{VJ}$, updated for 2017".

Based on a shell thickness of around $1 \mathrm{~mm}$ ( 0.040 inches) thick, the mass for each tank is approximately $80 \mathrm{~kg}$. This is thicker than a Centaur tank, but the Centaur tank requires thickness doublers to allow the system to be welded. So the feasibility of fabrication at that low of a thickness is an open question. The attachment of the SEMOV to the tank (assuming all loads pass through to the tank and SEMOV only supports it's own weight) is fairly simple and only requires thin tension straps that are thermally inconsequential to the total system heat load $(<1 \mathrm{~W})$.

In order to enable the capability of the vacuum vessel to passively hold for a duration of several years, the valve that isolates the vacuum vessel during flight must have essentially no leakage. Existing small pyro valves can be found with a leakage of $<1 \times 10^{-6}$ sccs of helium. For the expected volume of $1.46 \mathrm{~m}^{3}$ per tank, a leakage of $1 \times 10^{-6} \mathrm{sccs}$ of helium would be in the $3 \times 10^{-4}$ torr range

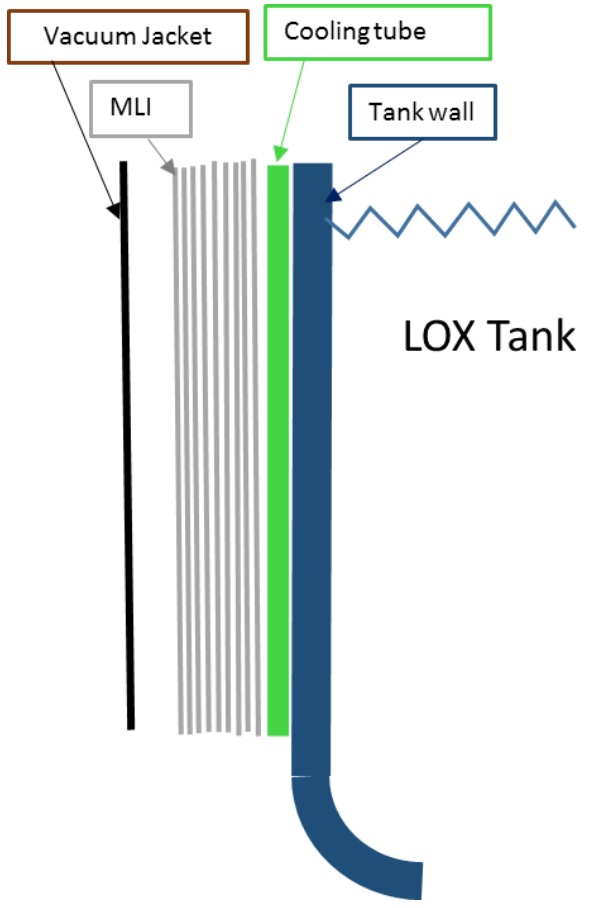

Figure 8: SEMOV insulation concept cross section. after 500 Martian days ( 24.5 hours each) starting off at a much lower pressure. While this would start to degrade the MLI performance, it would not cause it to go below a Knudsen number of 1 and start the steep increase associated with soft vacuum. This assumes a leakage of helium and not carbon dioxide, which is a much larger molecule and will leak much less than helium.

The operation of pyrotechnic valves on a mission is a common practice and as such is not individually an inherently risky operation. However, the evacuation of the vacuum vessel and insuring that the valve cross section is enough to 
evacuate the vessel would need to be demonstrated. To reduce the risk of small leaks developing and degrading insulation performance over time, and to allow recovery from crew repair of larger damaged areas that cause total vacuum failure, an active vacuum maintenance system has been proposed for further testing and development. Vacuum sensors, vacuum pumps, non-pyro valves, and control electronics would all be required, adding mass, power and reliability issues that would need to be traded against risk of propellant loss. Flight hardware is currently operating on Mars that could be adapted for each of these requirements.

\section{E. Earth Vacuum Jacket}

An Earth vacuum jacket would allow for simpler options than SEMOV, however, first order magnitude calculations based on the ASME Boiler and Pressure Vessel code, Section VIII suggested that the mass for each tank would be over $600 \mathrm{~kg}$ for each tank. ${ }^{4}$ Based on this mass alone, ( $2400 \mathrm{~kg}$ for the set of four tanks) the concept was thrown out as too heavy.

\section{F. Quest Load Responsive Multilayer Insulation}

Starting in 2008, Quest Product Development was awarded a series of SBIR awards that focused on lightweight vacuum jackets. Quest called the product Load-Responsive Multilayer Insulation (LR-MLI). LR-MLI is based on reflective layers that are separated by discrete standoff that are spaced intermittently between each layer. The standoff stack up and in a compressed mode, provide structural rigidity to the MLI blanket. They also can take up to 15 psi of compression onto an outer aluminum shell. Much effort was put into the design of the standoffs, but not necessarily the vacuum shell. This was demonstrated on a tank without the vacuum capability and holding up a broad area cooled shield in 2012 at Glenn Research Center, Quest called this implementation Load Bearing MLI (LB-MLI) (see Figure 9). ${ }^{9}$ For lack of a better term, in this study, the Quest product evaluated is referred to as LR-MLI.

In 2015, Quest started a new Phase I program focused on a hybrid of requirements associated with an insulation system that is evacuated during launch, similar to SEMOV, however, they focused on using their spacer designs to reduce the mass of the outer shell further. They developed a 3 mil single aluminized kapton and 2 mil aluminum foil laminate outer layer, which they supported with two different concepts: a spacing of IMLI posts and a spacing of LR-MLI posts. During testing, the IMLI posts buckled causing thermal shorts. Thermal performance ranged from $5-8 \mathrm{~W} / \mathrm{m}^{2}$ between boundary temperatures of $77 \mathrm{~K}$ and $295 \mathrm{~K}$. These have to be scaled for different warm boundary temperatures that would be encountered on Mars and suggest a heat flux of close to $2-3.5 \mathrm{~W} / \mathrm{m}^{2}$ (note this is scaling by a temperature exponent of 2.5 as opposed to an effective emmisivity assumption). The areal density was approximately $2 \mathrm{~kg} / \mathrm{m}^{2}$ for the better performing system and just under $1 \mathrm{~kg} / \mathrm{m}^{2}$ for the worse performing system.

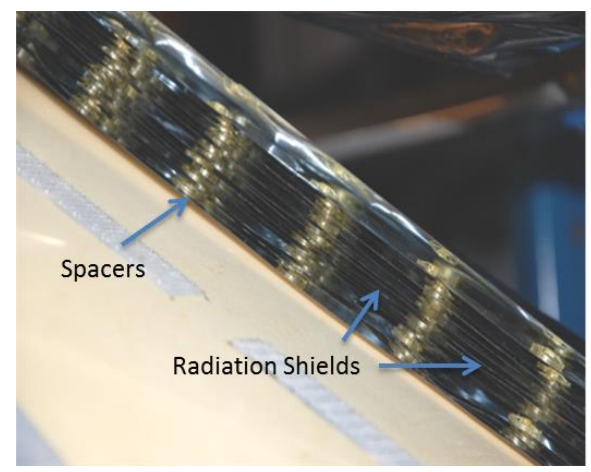

Figure 91: LB-MLI spacers stacked on a tank at GRC. 


\section{G. Multilayer Aerogel Insulation (MLAI) and SEMOV}

This concept was to put MLAI inside of the SEMOV as shown in Figure 11. The concept was to lower the risk and impact of loss of vacuum to the system by using a soft vacuum insulation inside the vacuum jacket (see Figure 10). Additionally, the aerogel would probably be able to take the compressive load at 10 torr (no analysis was done to verify this) and possibly eliminate the need for structural thermal shorts between the two tanks. This insulation concept would still give comparable performance to MLI at high vacuum but would lower the impact in case of loss of vacuum. The recent test data from Fesmire shows that this would not work, however, this trade was done before that test data was available to the team. ${ }^{7}$ For comparison purposes, the MLAI + SEMOV (or VJ) was assumed to have the mass of the SEMOV combined with the MLAI (as opposed to MLI) and the heat load of 1.5 times the SEMOV.

\section{H. Summary}

A summary of the mass and power needs for each option is shown in Table 1. These mass and power numbers were directly translated into the comparisons. The Figure of Merit (FOM) shown in the table, is merely the product of the areal density and the heat flux (lower values are better). The FOM was not used for any comparisons in the trade, but is useful for a general comparison between systems.

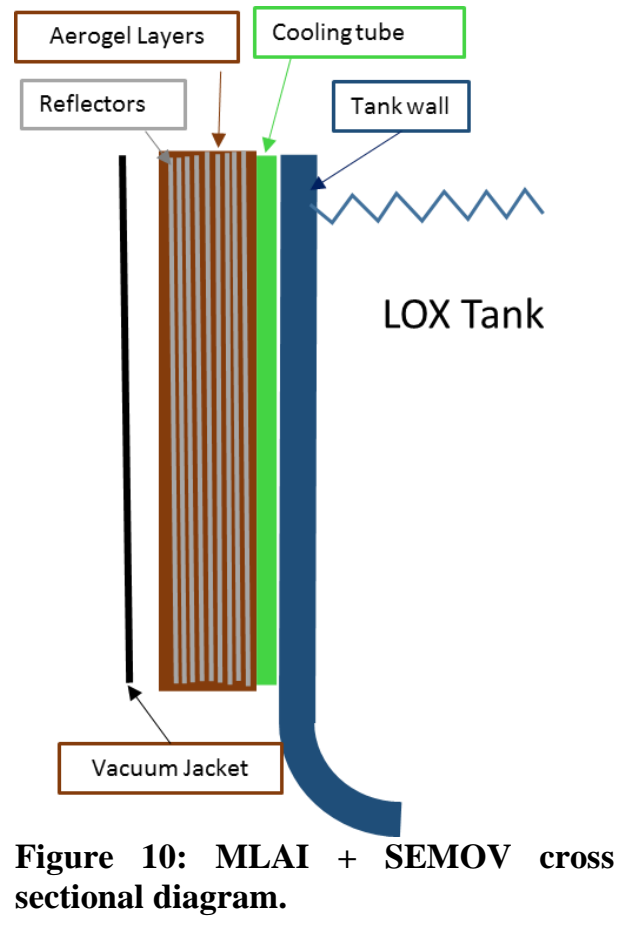

Table 1: Summary of mass and power results for each option.

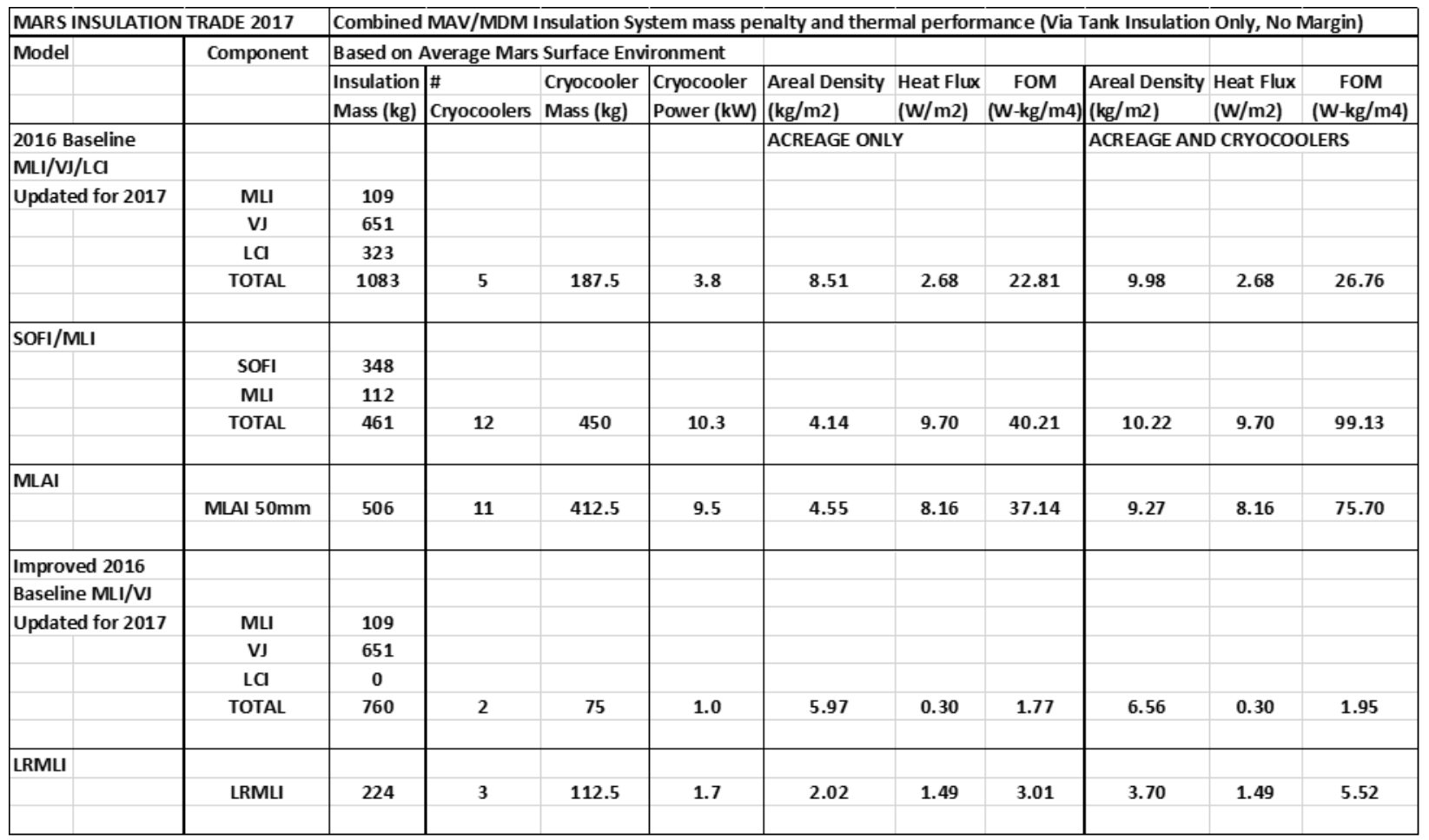

\section{Qualities and Traits Evaluated}

A total of six different qualities were identified. These were insulation system mass, active system power, insulation system cost, insulation system manufacturability, insulation system operational flexibility, and insulation 
system reliability. Great care was taking to concentrate the team on the insulation system as opposed to the entire system (with the exception of active system power). Active system power, is really how the insulation system interacts with the rest of the vehicle. Each of these are more fully developed in the following sections.

\section{A. Insulation System Mass}

The mass was defined as being the total mass of the insulation system being considered. The mass was developed as a part of the system level analysis more fully described in Section 2. It did not include the mass of any cryocoolers, power production, and heat rejection that might be involved with the system. It would include any hardware needed to make the insulation system work such as vacuum pumps, attachments, vacuum shells, etc. Lower masses were considered better than higher masses.

\section{B. Active System Power or Insulation Heat Load}

The power is a combination of both input (electrical) power and heat rejection (radiator) power, both of which are a function of the insulation system heat load. This metric could also be construed to contain cryocooler mass and also power system mass (which is a function of heat load) as it is an impact of having heat flowing through the insulation. The mass of these systems are much less well defined, as they will undergo their own internal trade studies to determine the best method(s) to provide the resources to other sub-systems. If the resources had allowed for it, full system mass trades would have been the preferred method to procede, however, that information was not available to the team. The lower the power was, the better the system scored.

\section{Insulation System Cost}

The cost metric took into account multiple sources of cost. Development cost is a function of the technology readiness level and degree of difficulty in advancing the Technology Readiness Level (TRL). This took into account the number of different components that would need development in addition to their current TRL. It also took into account expected cost of a flight unit. Lower cost was desirable.

\section{Insulation System Operational Flexibility}

Operational flexibility focused on how the system would operate in the environment provided. While initial analysis assumed constant temperatures, it is well known that this is not the case. Additionally, landing sites have not been chosen, nor will they be chosen for many years until after the technologies that need to be initially developed are developed. This means that the system needs to have operational flexibility. It needs to be able to handle the ebbs and flows of daily, seasonal, and other cycles. It needs to be able to operate in a range of locations. It needs to be simple to automate and be easy to control (whether this includes transfers between tanks, propellant conditioning, batch processing, or other variables). Additionally, it needs to be somewhat easy to develop transient thermal performance models for.

\section{E. Insulation System Manufacturability}

Manufacturability only references the ease of manufacturing a given system. It addresses the number of interfaces, how reasonable the manufacturing time frame would need to be, when the manufacturing is done in the full schedule and the ease of verifying the quality of manufacturing. It also addressed the ease of integrating all aspects of the flight solution (both hardware and software).

\section{F. Insulation System Reliability}

Reliability was the toughest metric to evaluate. Generally, reliability can take into account failure modes, part counts, risks associated with the system, and in this case, the ability to get humans off the surface with a nominal amount of warning. Additionally, degradation over time was taken into account including that of surface properties. Seeing as the liquefaction (and subsequent zero-boil-off) system is required to maintain the propellant conditions to allow for rapid crew evacuation, the reliability of the system becomes very important as a failure could jeopardize crew and mission safety.

\section{Evaluations}

Two separate evaluations were completed. First, the qualities and traits were evaluated against each other in order to develop the general importance of the qualities. Then the methodologies and solutions were traded against each other on each quality. Each trade was done pair wise, so that only two options were considered at a time. It was

American Institute of Aeronautics and Astronauics 
repeatedly emphasized that the transitive property did not apply and that each comparison should be done in a vacuum of itself, as much as possible.

Both evaluations were completed by the team over the course of several days while sitting together in a room and discussing the relative merits of the comparisons. The team does not assume that the results are final, but rather a starting point to initiate further discussion.

\section{A. Evaluation of Qualities and Traits}

Each trade was done pair wise, so that only two options were considered at a time. For instance, if the quality in the row was significantly better than the quality in the column, it was given a ten. If the methodology in the row was only slightly better, it was given a five. If both qualities were considered equal in meeting the metric, a 1 was given. If the row quality was considered slightly worse than the column quality, it received a 0.2 . Finally, if the row quality was considered significantly worse than the column quality it received a 0.1 . The results of all the pair wise trades of the criteria are shown in Table 2. The rows are then added up and normalized to the total number of points given in the "\%" column. A higher percentage of points scored would indicate a more important quality. The results of the weighting of the different traits are shown in Table 3. As an example, in the first row, "Insulation System Mass" was compared to "Active System Power", they were both considered equal, so a 1 is in the third column of that row. In the next column, "Insulation System Mass" was considered significantly more important than "Insulation System Cost", so it received a 10. Going to the next row, where "Active System Power" is compared to "Insulation System Mass", it receives a 1 (they were previously determined to be equal). The row below that where "Insulation System Cost" is compared to "Insulation System Mass", it receives a 0.1 as it is significantly less important than "Insulation System Mass".

Table 2: Results of evaluation of qualities and traits

\begin{tabular}{|c|c|c|c|c|c|c|}
\hline Weighting & $\begin{array}{c}\text { Insulation System } \\
\text { Mass }\end{array}$ & $\begin{array}{c}\text { Active System } \\
\text { Power }\end{array}$ & $\begin{array}{c}\text { Insulation System } \\
\text { Cost }\end{array}$ & $\begin{array}{c}\text { Insulation System } \\
\text { Manufacturability }\end{array}$ & $\begin{array}{c}\text { Insulation System } \\
\text { Operational } \\
\text { Flexibility }\end{array}$ & $\begin{array}{c}\text { Insulation System } \\
\text { Reliability }\end{array}$ \\
\hline $\begin{array}{c}\text { Insulation System } \\
\text { Mass }\end{array}$ & 1 & 1 & 10 & 5 & 1 & 0.2 \\
\hline $\begin{array}{c}\text { Active System } \\
\text { Power }\end{array}$ & 0.1 & 0.1 & 10 & 5 & 0.1 & 0.2 \\
\hline $\begin{array}{c}\text { Insulation System } \\
\text { Cost }\end{array}$ & 0.2 & 0.2 & 5 & 0.2 & 0.2 \\
\hline $\begin{array}{c}\text { Insulation System } \\
\text { Manufacturability }\end{array}$ & 1 & 1 & 10 & 5 & & 1 \\
\hline $\begin{array}{c}\text { Insulation System } \\
\text { Operational } \\
\text { Flexibility }\end{array}$ & 5 & 5 & 10 & 5 & & 1 \\
\hline $\begin{array}{c}\text { Insulation System } \\
\text { Reliability }\end{array}$ & 1 & & & 0.2 \\
\hline
\end{tabular}


As can be seen, there were three levels of importance. Reliability is the most important metric. Insulation system mass, active system power, and Insulation System Operational Flexibility were secondary metrics, in that they still scored over $20 \%$ of the points, but they were lower rated than reliability. Finally, cost, and manufacturability scored as the lowest importance. This does not imply that they are unimportant (they were important enough to be evaluated), but they are not nearly as important as the other metrics.

\section{B. Evaluation of Methodologies}

Each evaluation was done pair-wise, in that only two options were considered each time. Scores of $0.1,0.2,1,5$, and 10 were used. With the pair-wise comparison, the pairs end up as inversions of each other, so if one methodology gets a 5, the other gets a 0.2 . This methodology tends to be more successful in bringing out the high performers than equally distributing across worth.

If the methodology in the row was significantly better (considering the metric under evaluation only) than the methodology in the column, it was given a ten (and the item in the column a 0.1). If the methodology in the row was only slightly better, it was given a five. If both methodologies were considered equal in meeting the metric, a 1 was given (the inverse of 1 is 1 ). If the row methodology was considered slightly worse than the column methodology, it received a 0.2 . Finally, if the row methodology was considered significantly worse than the column methodology it received a 0.1 .

The mass comparisons are shown in Table 4 and the power comparisons in Table 5. The comparisons were fairly straight forward based on the summary masses shown in Table 1. Options with lower mass and power would considered better.

Table 4: Comparison of Mass of different options.

\begin{tabular}{|l|c|c|c|c|c|}
\hline $\begin{array}{l}\text { Insulation System Mass - The } \\
\text { total mass of the system being } \\
\text { considered. }\end{array}$ & Quest LRMLI & $\begin{array}{c}\text { Improved } \\
\mathbf{2 0 1 6} \mathbf{~ M L I / V J}\end{array}$ & MLAl & VJ + MLAI & SOFI/MLI \\
\hline Quest LRMLI & & $\mathbf{1 0}$ & $\mathbf{1 0}$ & $\mathbf{1 0}$ & $\mathbf{1 0}$ \\
\hline Improved 2016 MLI/VJ & 0.1 & & $\mathbf{0 . 2}$ & $\mathbf{5}$ & $\mathbf{0 . 1}$ \\
\hline MLAI & 0.1 & 5 & & $\mathbf{1 0}$ & $\mathbf{1}$ \\
\hline VJ + MLAI & 0.1 & 0.2 & 0.1 & 1 & $\mathbf{0 . 1}$ \\
\hline SOFI/MLI & 0.1 & 10 & 1 & 10 & \\
\hline
\end{tabular}

Table 5: Comparison of Power of different options.

\begin{tabular}{|l|c|c|c|c|c|}
\hline $\begin{array}{l}\text { Active System Power - Heat load } \\
\text { that the cryocooler rejects }\end{array}$ & Quest LRMLI & $\begin{array}{c}\text { Improved } \\
\mathbf{2 0 1 6} \text { MLI/VJ }\end{array}$ & MLAI & VJ + MLAI & SOFI/MLI \\
\hline Quest LRMLI & & $\mathbf{0 . 2}$ & $\mathbf{1 0}$ & $\mathbf{1}$ & $\mathbf{1 0}$ \\
\hline Improved 2016 MLI/VJ & 5 & & $\mathbf{1 0}$ & $\mathbf{5}$ & $\mathbf{1 0}$ \\
\hline MLAI & 0.1 & 0.1 & & $\mathbf{0 . 1}$ & $\mathbf{1}$ \\
\hline VJ + MLAI & 1 & 0.2 & 10 & & $\mathbf{1 0}$ \\
\hline SOFI/MLI & 0.1 & 0.1 & 1 & 0.1 \\
\hline
\end{tabular}

The comparison of expected costs are shown in Table 6. Cost estimates were not generated, however there were some discriminators. There is considered to be a significant developmental cost risk with the development of the lightweight vacuum jacketed options. SOFI and MLI was considered to have essentially zero development cost. The vacuum jacketed solutions would also cost more on a per-case basis than other solutions.

Table 3: Relative weightings based on the evaluation of the qualities and raits.

\begin{tabular}{|c|c|}
\hline Weighting & $\%$ \\
\hline $\begin{array}{c}\text { Insulation System } \\
\text { Mass }\end{array}$ & 20 \\
\hline $\begin{array}{c}\text { Active System } \\
\text { Power }\end{array}$ & 20 \\
\hline $\begin{array}{c}\text { Insulation System } \\
\text { Cost }\end{array}$ & 1 \\
\hline $\begin{array}{c}\text { Insulation System } \\
\text { Manufacturability }\end{array}$ & 21 \\
\hline $\begin{array}{c}\text { Insulation System } \\
\text { Operational } \\
\text { Flexibility }\end{array}$ & 31 \\
\hline $\begin{array}{c}\text { Insulation System } \\
\text { Reliability }\end{array}$ & 7 \\
\hline
\end{tabular}


Table 6: Comparison of cost of different options.

\begin{tabular}{|l|c|c|c|c|c|}
\hline $\begin{array}{l}\text { Insulation System Cost - general } \\
\text { ROM cost it may take to build this }\end{array}$ & Quest LRMLI & $\begin{array}{c}\text { Improved } \\
\mathbf{2 0 1 6} \mathbf{~ M L I / V J}\end{array}$ & MLAI & VJ + MLAI & SOFI/MLI \\
\hline Quest LRMLI & & $\mathbf{1}$ & $\mathbf{0 . 1}$ & $\mathbf{1}$ & $\mathbf{0 . 1}$ \\
\hline Improved 2016 MLI/VJ & 1 & & $\mathbf{0 . 2}$ & $\mathbf{1}$ & $\mathbf{0 . 1}$ \\
\hline MLAI & 10 & 5 & & $\mathbf{1 0}$ & $\mathbf{0 . 2}$ \\
\hline VJ + MLAI & 1 & 1 & 0.1 & 0.1 \\
\hline SOFI/MLI & 10 & 10 & 5 & 10 \\
\hline
\end{tabular}

The comparison of insulation system manufacturability is shown in Table 7. The manufacturing of a vacuum jacket or Quest product would be more difficult and time intensive than either an aerogel of Foam/MLI solution. Manufacturing of the SOFI and MLI is well known. Though these would be smaller tanks than usually sprayed, tanks this size have been sprayed for research purposes multiple times.

Table 7: Comparison of manufacturability of different options.

\begin{tabular}{|c|c|c|c|c|c|}
\hline $\begin{array}{l}\text { Insulation System } \\
\text { Manufacturability - How easy the } \\
\text { system will be to manufacture } \\
\text { and integrate onto spacecraft }\end{array}$ & Quest LRMLI & $\begin{array}{c}\text { Improved } \\
2016 \mathrm{MLI} / \mathrm{VJ}\end{array}$ & MLAI & VJ + MLAI & SOFI/MLI \\
\hline Quest LRMLI & & 0.2 & 0.1 & 0.2 & 0.1 \\
\hline Improved $2016 \mathrm{MLI} / \mathrm{VJ}$ & 5 & & 0.1 & 1 & 0.1 \\
\hline MLAI & 10 & 10 & & 10 & 0.2 \\
\hline $\mathrm{VJ}+\mathrm{MLAl}$ & 5 & 1 & 0.1 & & 0.1 \\
\hline SOFI/MLI & 10 & 10 & 5 & 10 & \\
\hline
\end{tabular}

The comparison of operability flexibility is shown in Table 8 , the basic assumption in this is that everything is operating nominally. The higher performing vacuum jacketed materials were considered more robust against fluctuation in performance with environmental temperature and location. Variation in temperature would require the SOFI or MLAI to be designed thicker than optimal to prevent $\mathrm{CO}_{2}$ sublimation in the worst environments. The SOFI would be more sensitive to this than the MLAI would be due to poorer performance.

Table 8: Comparison of operational flexibility of different options.

\begin{tabular}{|l|c|c|c|c|c|}
\hline $\begin{array}{l}\text { Insulation System Operational } \\
\text { Flexibility - The flexibility of the } \\
\text { system to operate in a wide range } \\
\text { Of environments. }\end{array}$ & Quest LRMLI & $\begin{array}{c}\text { 2016 MLI/VJ } \\
\text { Improved }\end{array}$ & MLAI & VJ + MLAI & SOFI/MLI \\
\hline Quest LRMLI & & $\mathbf{1}$ & $\mathbf{5}$ & $\mathbf{1}$ & $\mathbf{1 0}$ \\
\hline Improved 2016 MLI/VJ & 1 & & $\mathbf{1 0}$ & $\mathbf{1}$ & $\mathbf{1 0}$ \\
\hline MLAI & 0.2 & 0.1 & & $\mathbf{0 . 2}$ & $\mathbf{5}$ \\
\hline VJ + MLAI & 1 & 1 & 5 & & $\mathbf{1 0}$ \\
\hline SOFI/MLI & 0.1 & 0.1 & 0.2 & 0.1 & \\
\hline
\end{tabular}

The comparison of insulation system reliability is shown in Table 9. Quest has had significant issues with trying to seal their insulation systems up. A more traditional vacuum jacket, while lighter may have similar issues depending on the thickness of the outer shell, but as a solid welded metal jacket, would be better than the Quest systems. Insulation systems without a sealed jacket would be much more reliable with less failure mechanisms, less moving parts, and less environmental event sensitivity (i.e. rocks rolling around in a dust storm). The team currently has very 
little confidence in the level of the Quest system but thinks that with development both it and the lightweight vacuum jackets could be made to operate reliably.

Table 9: Comparison of insulation system reliability of different options.

\begin{tabular}{|l|c|c|c|c|c|}
\hline $\begin{array}{l}\text { Insulation System Reliability - } \\
\text { Predicted events during life that } \\
\text { may impede success of } \\
\text { operations }\end{array}$ & Quest LRMLI & $\begin{array}{c}\text { Improved } \\
\mathbf{2 0 1 6} \text { MLI/VJ }\end{array}$ & MLAI & VJ + MLAI & SOFI/MLI \\
\hline Quest LRMLI & & $\mathbf{0 . 2}$ & $\mathbf{0 . 1}$ & $\mathbf{0 . 2}$ & $\mathbf{0 . 1}$ \\
\hline Improved 2016 MLI/VJ & 5 & & $\mathbf{0 . 1}$ & $\mathbf{0 . 1}$ & $\mathbf{0 . 1}$ \\
\hline MLAI & 10 & 10 & & $\mathbf{5}$ & $\mathbf{1}$ \\
\hline VJ + MLAI & 5 & 10 & 0.2 & & $\mathbf{0 . 2}$ \\
\hline SOF/MLI & 10 & 10 & 1 & 5 & \\
\hline
\end{tabular}

\section{Results}

Combining the results of the evaluation of the metrics and the evaluation of the methodologies gives a view into the relative capabilities of each of the methodologies of solving the problem at hand. Table 10 shows the relative point scores as originally scored. Table 11 shows the breakdown of where the points were scored and is color coded from dark green (most points scored) to dark red (least points scored) to help visualize where the points were scored. There is a clear dichotomy seen in the results: insulation solutions were either good in active system power (i.e. had a low heat load) or reliability. If the system was good in one of the two catagories, they were poor in the other. As these were two of the most important catagories, this meant that there were no winners of the trade study. However, it was clear based on the results that the lightweight vacuum jacket based sysems such as the Quest solution were significantly lighter than the other options. Thus development work should focus on improving the reliability of these systems.

Table 11: Relative results for each of the components of the scoring

\begin{tabular}{|c|c|c|c|c|c|c|}
\hline $\begin{array}{l}\text { Relative Scoring } \\
\text { Results }\end{array}$ & $\begin{array}{c}\text { Insulation System } \\
\text { Mass }\end{array}$ & $\begin{array}{l}\text { Active System } \\
\text { Power }\end{array}$ & $\begin{array}{c}\text { Insulation System } \\
\text { Cost }\end{array}$ & $\begin{array}{l}\text { Insulation System } \\
\text { Manufacturability }\end{array}$ & $\begin{array}{c}\text { Insulation System } \\
\text { Operational } \\
\text { Flexibility }\end{array}$ & $\begin{array}{c}\text { Insulation System } \\
\text { Reliability }\end{array}$ \\
\hline Quest LRMLI & 0.0976 & 0.0573 & 0.0002 & 0.0005 & 0.0582 & 0.0025 \\
\hline Improved $2016 \mathrm{MLI} / \mathrm{VJ}$ & 0.0132 & 0.0811 & 0.0002 & 0.0054 & 0.0753 & 0.0222 \\
\hline MLAI & 0.0393 & 0.0035 & 0.0027 & 0.0264 & 0.0188 & 0.1088 \\
\hline $\mathrm{VJ}+\mathrm{MLAI}$ & 0.0012 & 0.0573 & 0.0002 & 0.0054 & 0.0582 & 0.0644 \\
\hline SOFI/MLI & 0.0515 & 0.0035 & 0.0037 & 0.0306 & 0.0017 & 0.1088 \\
\hline
\end{tabular}

American Institute of Aeronautics and Astronauics 


\section{Conclusion}

Insulation systems such as traditional vacuum jackets, low-pressure vacuum jackets, and soft vacuum insulation systems such as aerogel were considered. As zero-boil off and liquefaction operations were assumed, all heat load manifest itself as increased cryocooler mass and power as opposed to boil-off. The trade showed that for low mass, low (cryocooler) power options, the reliability was deemed poor in it's current state. However, highly reliable systems had significantly more mass (hundreds of $\mathrm{kg}$ on the Mars Ascent vehicle). As such, risk reduction measures to increase the reliability of these systems will be investigated in the hopes of realizing the mass gain for the low mass options.
Table 12: Results of cumulative scoring with active power increased to be more important than mass.

\begin{tabular}{|l|c|}
\hline $\begin{array}{l}\text { Relative Scoring } \\
\text { Results }\end{array}$ & $\begin{array}{c}\text { \% of total points } \\
\text { scored }\end{array}$ \\
\hline Quest LRMLI & 22 \\
\hline Improved $2016 \mathrm{MLI} / \mathrm{VJ}$ & 22 \\
\hline $\mathrm{MLAI}$ & 18 \\
\hline VJ + MLAI & 20 \\
\hline SOFI/MLI & 18 \\
\hline
\end{tabular}

\section{Acknowledgments}

This study was funded by the Lander Technologies project, a part of NASA's Advanced Exploration Systems Program.

\section{References}

${ }^{1}$ S.D. Augustynowicz and J.E. Fesmire, "Cryogenic Insulation System for Soft Vacuum," in Advances in Cryogenic Engineering, Vol. 45, vol. 45, NY, Kluwer Academic/Plenum Publishers, 2000, pp. 1445-1451.

${ }^{2}$ Personal communications with Stan Starr and Gabe Merrill.

${ }^{3}$ T. Polsgrove, H.D. Thomas, W. Stephens and M.A. Rucker, "Mars Ascent Vehicle Design for Human Exploration," in AIAA-2015-4416, 2015.

${ }^{4}$ D.M. Hauser, W.L. Johnson and S.G. Sutherlin, "Liquefaction and Storage of In-Situ Oxygen on the Surface of Mars," in AIAA SciTech 2016, AIAA-2016-0721, 2016.

${ }^{5}$ J.J. Martin and L.J. Hastings, "Large Scale Liquid Hydrogen Testing of a Variable Density Multilayer Insulation with a Foam Substrate," 2001.

${ }^{6}$ S. White, R. Begag, D. Mihalcik, J.E. Fesmire, J.L. Kerce, G. Mills, L. Buchanan and S. Buerger, "Multi-Layer Aerogel Insulation for Cryogenic Applications," in Presented at the 2015 Cryogenic Engineering Conference, Tuscon, AZ, 2015.

${ }^{7}$ J. Fesmire, J. Ancipink, A. Swanger, S. White and D. Yarbrough, "Thermal Conductivity of Aerogel Blanket Insulation Under Cryogenic-Vacuum Conditions in Different Gas Environments," Presented at the 2017 Cryogenic Engineering Conference, Madison, WI, 2017.

${ }^{8}$ D.W. Plachta, S.P. Tucker and D.J. Hoffman, "Cryogenic Propellant Thermal Control System Design Considerations, Analyses, and Concepts Applied to a Mars Human Exploration Mission," AIAA-93-2353, 1993.

${ }^{9}$ D. W. Plachta, W.L. Johnson and J.R. Feller, "Cryogenic Boil-off Reduction System Testing," in AIAA 2014$3579,2014$. 